\title{
A LITERATURA COMO ELEMENTO PROPULSOR DE INTERPRETAÇÕES DIVERSAS
}

\author{
Auzelene Miranda Gusmão ${ }^{1}$ \\ Edleuza Fernandes Barbosa²
}

\begin{abstract}
Resumo
Esta pesquisa apresenta como tema "A Literatura Como Elemento Propulsor de Interpretações Diversas" e tem como objetivo discutir sobre a importância da leitura literária para a formação intelectual e social do discente, porque exerce um papel primordial no processo de formação do educando. O leitor que lê o que está na obra e que percorre o caminho da releitura consegue perceber um desdobramento de percepções subjetivas, as quais irão desaguar em sua experiência de leituras anteriores, o que o leva a armazenar conhecimento para a possível "intertextualidade", relação entre textos e contextos, e que pressupõe outras formas de conhecimento vinculadas à literatura. Para realizar este trabalho empregou-se como metodologia a pesquisa bibliográfica procurando demonstrar de forma clara e precisa as inquietações que permearam as dificuldades da leitura literária para os discentes, tendo em vista os métodos, objetivos, dados e deduções acerca da temática, que está longe de ser esgotada devida à pertinência do tema para o âmbito educacional. Conclui-se que a leitura literária ativa o imaginário, proporcionando o desenvolvimento da reflexão e de uma melhor compreensão de nosso interior e do mundo.
\end{abstract}

Palavras Chaves: Ler. Literatura. Discente.

\begin{abstract}
This research has as its theme "Literature as a Propelling Element of Diverse Interpretations" and aims to discuss the importance of literary reading for the intellectual and social formation of the student, because it plays a major role in the process of training the student. The reader who reads what is in the work and walks the path of re-reading can perceive an unfolding of subjective perceptions, which will flow into his experience of previous readings, which leads him to store knowledge for the possible "intertextuality", relationship between texts and contexts, and that supposes other forms of knowledge linked to literature. To carry out this work, bibliographic research was used as methodology, trying to demonstrate clearly and precisely the concerns that permeated the difficulties of literary reading for students, considering the methods, objectives, data and deductions about the theme, which is far away exhausted due to the relevance of the topic to the educational field. It is concluded that literary reading activates the imaginary, providing the development of reflection and a better understanding of our interior and the world.
\end{abstract}

Keywords: Reading. Literature. Student.

\section{Introdução}

Esta pesquisa faz abordagens sobre a leitura literária e suas influências; o tear do texto literário e o conhecimento da língua bem como a literatura no espaço escolar.

\footnotetext{
${ }^{1}$ Mestra em Ciências da Educação pela Faculdade Interamericana de Ciências Sociais - FICS; Especialista em Literatura Brasileira pela PUC-MINAS; Graduada em Letras Vernáculas pela UESB Universidade Estadual do Sudoeste da Bahia. .Email: auzelene@yahoo.com.br

${ }^{2}$ Mestra em Ciências da Educação pela Facultad Interamericana de Ciências Sociales - FICS. Pósgraduada em Organização e Processos do Ensino Superior pela União Intermunicipal de Cursos Superiores da Bahia - UNIBA. Especialista em Psicopedagogia: institucional, clínica e hospitalar pela Faculdade Católica de Ciências Econômicas da Bahia - FACCEBA. Graduada em Pedagogia pela Universidade Católica do Salvador - UCSAL. Graduada em Letras Vernáculas pela Universidade Federal da Paraíba - UFPB. Email:dhillyfernandes@gmail.com.
} 
Ela destaca a leitura literária como reconstrutora de si mesmo, do indivíduo, a ponto de ser ela, a literatura, capaz de reordenar a interioridade do ser humano e dar-lhe um sentido de continuidade. Muitos personagens das obras literárias foram traçados, construídos com base na vida real, uma transfiguração da realidade, daí o encontro mágico com esses elementos de dentro do texto que se fazem presentes desde então no contexto de fora, o da realidade.

Ler literatura integra o indivíduo ao ambiente de proatividade intelectual e nele, promove-se possibilidades interpretativas e reflexivas sobre os diversos 'mundos'. O contato com as vertentes literárias deve proporcionar um entranhamento nas camadas mais favoráveis de aprendizagem, levando-o ao autoconhecimento, o que o possibilitará participar e multiplicar elementos de valor subjetivo e objetivo. O saber literário pautado nas interpretações plurissignificativas, característica de si mesma, desobstrui no mínimo as entradas e canais físicos que podem ser traduzidos em metáforas.

O escritor modernista, Monteiro Lobato, em uma de suas produções poéticas expôs que o ouvir, falar e ver são elementos de captação e reprodução de conhecimento adquirido e que a ausência da leitura distorce o entendimento e a reflexão que poderia vir a ser aprimorada, pois "a leitura do mundo precede a leitura da palavra" (FREIRE, 2000, p.11). A partir das necessidades colhidas na leitura anterior, a segunda terá uma perspectiva mais acentuada em direção ao acolhimento do que está inserido nas letras e que interpretadas retornarão com uma carga semântica capaz de proporcionar relações interdisciplinares de grande valor.

O baixo nível de leituras em torno das obras literárias desde a educação básica até o ensino médio pode ser um influenciador de dificuldades encontradas pelos alunos em áreas de humanas e exatas. Essas dificuldades podem vir a ser um dos pontos de castração das leituras de mundo e das intertextualidades. De acordo com Zilberman e Silva, (1990, p. 19)

O texto literário introduz um universo que, por mais distanciado do cotidiano, leva o leitor a refletir sobre sua rotina e a incorporar novas experiências (...) o texto artístico talvez não ensine nada, nem se pretenda a isso; mas seu consumo induz a algumas práticas socializantes que, estimuladas, mostramse democráticas, porque igualitárias. 
Partindo do princípio de que educar presume globalidade, percebe-se a necessidade de reintroduzir o caráter da leitura literária como sendo este um dos princípios de coesão, relação entre as multifaces da aprendizagem. Ler, interpretar e relacionar são elementos propulsores de conhecimento, o que eleva o nível de aprendizagens diversificadas capazes de promover no aprendiz um cenário multifocal.

\section{A leitura Literária e Suas Influências}

A leitura literária tem um papel preeminente no desenvolvimento social, cultural e intelectual do indivíduo, principalmente na formação do leitor que, em processo de graduação dessa leitura, se aprofunda em caminhos diversificados e que significativamente o conduz a mundos cada vez mais múltiplos. Temos, então, um prérequisito fundamental para que se torne um leitor maduro, capaz de estender-se em significados a tantos outros universos de conhecimentos e multiplicá-los na ordem de suas vivenciações. Essa bagagem particular pode ser compartilhada no momento em que a relação ambivalente, leitor/mundo, já não caiba mais em si, uma vez ter ganhado corpo e significado, alertando de que é chegada a hora de retransmiti-los como prática social.

Ao aluno do ensino médio, que se encontra em estágio mais avançado no processo de leitura literária, faz-se necessário dialogar com o letramento literário, uma vez ser esse mecanismo um dos responsáveis pela qualidade a ser aplicada no trânsito que vai desde o contato com o texto, até seu esgotamento interpretativo. Em buscando trabalhar a prática dos estudos literários em sala de aula, cabe apreciar um outro juízo que é o de desvincular prazer ao de cobrança quantitativa, e aqui chamamos de avaliações que são designadas em sua grande maioria a especularem o texto tão somente em sua constituição enquanto gênero, conceito literário, evadindo do princípio da sua especialidade que se estende em significados, interpretações paralelas, intertextualidades e o que mais lhe for expressivo.

O processo de letramento no campo escolar, deve ser produzido com vistas a conduzir o (a) estudante/leitor a um nível de consideração textual que vise a sua integralidade. Ao ler o texto, o aluno/a não deve permanecer nesse simples ato, mas ser capaz de compreendê-lo e avançar no processo de somar a ele outros significados. No entanto, para que esse processo seja de fato estabelecido com propriedade, alguns fatores devem ser alterados e/ou regulamentados como prática 
livre do mecanismo conteudista, que limita e desconfigura o verdadeiro sentido que reside na literatura.

Ler e interpretar o texto literário é o verdadeiro sentido da escolarização literária, é preciso trabalhar o aluno/a para que este esteja apto a traduzir o que a literatura promove, e a escola, intermediada pelo professor da disciplina, pode desenvolver mecanismos de aprendizagens que canalizem para a leitura significativa, experiência a que se espera chegar. Letramento literário e escolarização literária são condições desenvolvidas com fins de formar leitores capazes de humanizar a literatura no campo escolar e mais precisamente, no objeto de conhecimento. Para Cosson, (2009, p. 90)

Letramento literário pode ser definido, em linhas gerais, como um conjunto de práticas e eventos sociais que envolvem a interação leitor e escritor, produzindo o exercício socializado na escola por meio da leitura de textos literários, sejam estes canônicos ou não. Assim a finalidade principal é a construção e reconstrução dos significados em relação ao texto literário lido dentro ou fora da sala de aula.

O letramento literário deve abranger feitios que harmonizem os distintos textos literários circundantes nas esferas sociais. A importância do ato de ler é algo comumente veiculado em nível acadêmico, tema relevante para a aquisição de conhecimento e até mesmo de referência curricular em meio ao grupo seleto de leitores bem formados e amparados pelos discursos literários absorvidos e internalizados. Cada um desses leitores está amparado pelo processo de formalização a que se deu a sua acuidade linguística, interpretativa e intelectual advinda da exposição aos livros lidos e debulhados. A literatura, "não apenas formula e expressa o que diz, mas também quer influenciar a postura do leitor, persuadi-lo e, por fim, modificá-lo (WELLEK E WARREN, 2003).

No que tange à literatura, o processo de modificação a que está sujeito o leitor, configura-se em um dos elementos de maior importância a que se deseja chegar, modificar-se é o mesmo que promover uma reconstrução de si mesmo e permitir que elementos de reflexões sejam utilizados como ferramenta de transformação. Refletir, interpretar o mundo e a si próprio traz um sentimento de prosseguimento, de avanços significativos e dinâmicos rumo ao conhecimento, ao saber. Para Dias, (2017, p.48).

A literatura, nos mostra como era antes, isto é, os problemas que se passavam na sociedade na época em que foram escritos, ou seja, os autores escreviam isso para que a sociedade pudesse refletir e mudar a situação. (...), a literatura além de trazer conhecimento da época em que a mesma foi escrita, faz a gente refletir nos dias de hoje também. 
Ler literatura deve ser uma prática de caráter constante e considerada como critério fundamental para o desenvolvimento de inúmeras outras habilidades como em qualquer outro processo de aprendizagem. Para Paulino (2004, p. 47)

\begin{abstract}
A leitura se diz literária quando a ação do leitor constitui predominantemente uma prática cultural de natureza artística, estabelecendo com o texto lido uma interação prazerosa. O gosto da leitura acompanha seu desenvolvimento, sem que outros objetivos sejam vivenciados como mais importantes, embora possam também existir. O pacto entre leitor e texto inclui, necessariamente, a dimensão imaginária, em que se destaca a linguagem como foco de atenção, pois através dela se inventam outros mundos, em que nascem seres diversos, com suas ações, pensamentos, emoções.
\end{abstract}

A linearidade e a constância devem surgir ainda cedo, em idade lúdica, a fim de que se possa desenvolver o gosto pela leitura e que, a partir desse movimento de influências, um leitor comece a ser formado, abrindo espaço para a fomentação dessa prática para outros níveis. Inclusive o de intertextualidades, campo vasto e diversificado para o alcance até mesmo de relações inusitadas, daí a importância de ler literatura no Ensino Médio, uma vez que a sua prática faz alcançar outros destaques, a exemplo, a boa escrita que é fruto da prática de leitura.

Sendo a literatura uma fonte significativa de conhecimento, mas também de ludicidade, nota-se que essa importância deve ser introduzida na infância, reconhecendo que através do brincar também se aprende. Cândido (1995, p. 39) afirma que:

\begin{abstract}
A Literatura desenvolve em nós a sensibilidade, tornando-nos mais compreensivos, reflexivos, críticos e abertos para novos olhares e possibilidades diante da nossa condição humana. A leitura literária permitenos refletir sobre o mundo em nossa volta, abrindo nossos horizontes, ampliando os conhecimentos, possibilitando novas perspectivas.
\end{abstract}

A ressalva que aqui se faz é a de que o texto literário está repleto de elementos sugestivos, significativos e imagéticos, todos eles construídos a partir do leitor ou até mesmo de um contador de história que, habilitado, pode proporcionar aos ouvintes mirins o desfrute lúdico, quando na fala dos personagens, executa malabarismos de voz que trazem individualidade e diferença a cada um deles.

É possível contar com as fábulas que encantam pela peculiaridade de trazer vida e voz a seres inanimados e que encantam com as impossibilidades que a realidade não permite, mas que estão todos libertos no campo das narrativas literárias e em qualquer outro gênero. Tudo cabe na literatura, a brincadeira com o texto, a 
imaginação criadora e a interpretação a partir do seu conhecimento de mundo (ABRAMOVICH, 1995).

$\mathrm{Na}$ mesma ordem, existem os sentimentos que são experimentados e traduzidos no instante em que a relação leitor/texto se estabelece e que o texto brincado não extingue o seu valor e a sua função, o que temos é uma modalidade de leitor diferenciada e que precisa ser atendida dentro de uma expressão qualitativa própria para a fase inicial. Deve-se atentar para a temática a ser escolhida nesse momento, bem como a idade e a apresentação do texto (estética), fatores relevantes para desenvolver o gosto pela leitura.

Sabe-se que a racionalização do elemento literário chegará mais tarde e será tratada com outra identidade a partir da socialização que esse leitor estará submetido. Alguns estarão amadurecidos, outros em fase de inúmeros confrontos com as opções de gênero a que poderá fazer, porém tantos outros terão desistido da continuidade a que a literatura promove deixando-se levar pela informalidade literária ainda em nível escolar de ensino médio, momento crítico pela necessidade de aprontar-se para o movimento de seleção à entrada na Universidade. Para Azevedo, (2007, p. 18)

\begin{abstract}
A leitura do texto literário no ensino médio é, sem dúvida, muito importante para o aluno nesta fase de sua formação escolar. O texto literário promove um encontro especial com a leitura, pois através do contato com a literatura o aluno descobre as múltiplas faces da linguagem, entra em contato com diferentes aspectos da Língua Portuguesa. Quanto maior for a diversificação dos textos literários apresentados aos alunos, maior será a experiência que ele terá com este universo de singular beleza, magia e emoção.
\end{abstract}

Nesse período, os níveis de leitura se esbarram nas cobranças de um leitor que corresponda ao que os exames classificatórios exigem, e que o tempo e a necessidade Ihes são muito mais importantes do que a apreciação do texto literário, seguido de discussões e reflexões sobre ele, a ludicidade e o prazer pela obra, agora são esvaziados e ocupados pela urgência do cumprimento de tarefas. Os resumos prontos das leituras passam a ser a leitura principal, não é mais necessário sentir, imaginar ou refletir sobre enredo, a forma mais prática é memorizar os elementos mais significativos tais como personagens, cenário, períodos e minimamente a que se relaciona o tema, a essa altura a interpretação já não faz parte do contexto de erros e acertos, mas desnecessário para a sua classificação na lista de seleção dos candidatos aprovados. 
A literatura promove graus de conhecimentos que permeiam uma singularidade e uma pluralidade ao mesmo tempo. O singular está para o posicionamento do leitor ante a sua visão de mundo particular que refletirá na análise interpretativa das leituras praticadas, essas são intransferíveis e serão unicamente enxergadas.

Por outro lado, a pluralidade será a sua extensão, a sua relação estendida a outros níveis e planos também de interpretação e análise. O leitor se dará conta de que outros universos giram em torno com afinidades e com extensões significativas. (PEREIRA, 2009).

O valor da família na formação do leitor é imprescindível, mesmo sendo ele analfabeto, porém incentivado e motivado por essa família, esse leitor será formado. Cita também outros mecanismos de participação além da família que contemplam essa formação que são os professores, bibliotecários e de maneira mais direta, o próprio entusiasmo e o comprometimento, ações de grande relevância e que independe da materialidade presente. (CEREJA, 2005).

Partindo da prerrogativa de que mesmo havendo um esvaziamento de recursos materiais para a abordagem e exercício da prática de leitura literária, e que o entusiasmo e o comprometimento servem como propulsão para esse encadeamento literário, questionamos então o porquê de tantas dificuldades encontradas nos alunos do ensino médio, referentes a essas práticas. Quais seriam os verdadeiros motivos que interferem e se estabelecem como obstáculos, levando-os a um distanciamento das obras literárias, bem como a própria falta de interesse em interagir e vivenciar a realidade artística e cultural que a literatura promove?

\section{O Leitor, o Tear do Texto Literário e o Conhecimento da Língua}

Uma das tarefas da leitura de literatura é a de conceber, e de forma livre, um leitor consciente de que essa literatura não é apenas mais uma em seu rol, mas a de que traz conhecimento vasto quando aplicada em ritmo de análise participativa, ou seja, o leitor participa da construção subjetiva do texto quando da interpretação dos elementos que o estabelece, ele tece o texto no momento em que lança mão do seu nível de conhecimento e que, atrelados, farão brotar saberes muitas vezes inusitados para si. Cândido, (1995, p. 28) afirma que 
A Literatura desenvolve em nós a sensibilidade, tornando-nos mais compreensivos, reflexivos, críticos e abertos para novos olhares e possibilidades diante da nossa condição humana. A leitura literária permitenos refletir sobre o mundo em nossa volta, abrindo nossos horizontes, ampliando os conhecimentos, possibilitando novas perspectivas.

Tecer um texto é o mesmo que levar para dentro dele o conhecimento que em algum momento já foi adquirido, a exemplo, o tipo de texto, as suas implicações como gênero, estilo, perfil do autor e da obra, tarefa relevante para construir novos saberes, no entanto, é necessário salientar que essas informações técnicas se estabelecem na curiosidade que o leitor desejoso tem para com o texto e os seus saberes, e que trarão fundamentações importantes para a sua compreensão e extração de sentidos.

Outro ponto de reflexão quanto à aquisição de conhecimento através da literatura é o saber sobre si, transitar entre a estrutura técnica na qual a literatura foi construída e na audição da fala textual, repleta de características que contribuem para suscitar a subjetividade do leitor quando lhe é permitida e que o enriquece na medida em que esse diálogo é estabelecido. O aluno deve ser capaz de compreender esse processo de reciprocidade e equivalência para não acreditar que o texto e ele próprio são elementos isolados no processo de ação ou o de que exercem funções puramente unilaterais de apreciação, o que não estaria vinculado ao processo de tecer o texto e tecer a si próprio concomitantemente (LAJOLO, 2008).

O poeta João Cabral de Melo Neto, em sua poesia intitulada - Tecendo a manhã - retrata metaforicamente a ação do leitor na figura representativa do galo para com o texto a ser decifrado. Esse leitor representado faz a construção textual a partir das suas inferências advindas de sua leitura de mundo e que, sugeridas pela elucidação do texto, vão promovendo em conjunto uma outra realidade por vias de entrelaçamentos. Há uma convergência de saberes nesse processo de tecelagem e que resulta em novas abordagens, significados. Para o poeta modernista, Neto, (1975, p. 19)

\footnotetext{
Um galo sozinho não tece uma manhã; ele precisará sempre de outros galos. De um que apanhe esse grito que ele e o lance a outro; de um outro galo que apanhe o grito que um galo antes e o lance a outro; e de outros galos que com muitos outros galos se cruzem os fios de sol de seus gritos de galo, para que a manhã, desde uma teia tênue, se vá tecendo, entre todos os galos.
}

Nota-se que no fragmento do poema de João Cabral de Melo Neto, texto e leitor devem ser entendidos como agentes ativos, um interagindo com o outro e o leitor/a retransmitindo socialmente, através da sua experiência objetiva (técnicas textuais) e 
subjetivas (saberes depreendidos do texto) os princípios fundamentais que essa literatura o proporciona. O/a aluno/a do ensino médio muitas vezes não compreende que esse processo de ambivalência é gradual e que é necessário ter interesse participativo que será responsável em conduzi-lo à experiência de avanço no processo de conhecimento, interpretação e significado.

Observa-se que existe nesse procedimento técnico e subjetivo o caráter da dualidade, convergência e divergência, o ir e vir do leitor no texto, bem como do texto para com o leitor, o que configura conhecimento, prazer e até possíveis desconstruções outrora formadas e que agora abre novos espaços significativos de interpretação.

O leitor/a do ensino médio deve estar a par desse movimento, uma vez estar apto como crítico capaz de traduzir os elementos sinalizados em sua compreensão de que não se desmistifica os pressupostos do texto literário sem o mecanismo de amadurecimento tão necessário para esse momento, o que o torna capaz de ser classificado nos níveis a que se destina. Para Jauss, (1993, p.28)

\begin{abstract}
As aulas de Literatura têm de ser projetadas para a liberdade e o prazer, respeitando a livre interpretação do aluno, que é resultado da sua história, da sua leitura de mundo, bagagem que é carregada por ele e que não pode ser dissociada quando lê. Ajudar a construir o sentido da leitura em uma turma no Ensino Médio é um processo subjetivo, que necessita respeitar a individualidade que é ser adolescente na sociedade atual.
\end{abstract}

Tecer o texto literário é o mesmo que interagir leitor e texto, união de pertinência que estabelece significados à medida que cresce e se torna íntima, ambos se revelando um ao outro. É nesse instante em que ao leitor será apresentado elementos motivadores que fazem toda diferença na construção de um pensamento mais apurado, capaz de interpretar e ressignificar elementos de saliência presentes no próprio texto e enxergar outros nele mesmo e em tantos que couber. Para Zilberman, (2012, p.210)

O foco da Literatura, no Ensino Médio, tem de ser a formação do leitor, oportunizando que o estudante atribua sentido aos textos lidos nas aulas, desenvolvendo críticas baseadas no contexto histórico e social que surjam devido à leitura, que precisa ser o centro de toda e qualquer discussão a respeito de uma obra literária.

O importante é dar significado ao texto é onde se espera que o leitor crítico do ensino médio chegue, é o que se almeja com o estudo de literatura nesse nível de escolaridade e em outros tantos lugares em que lhe caiba. $E$ onde a literatura não 
pode ser inserida? Em que espaço a literatura não pode pertencer? A literatura não será retransmitida onde o leitor de significados, de mundo e crítico não se fizer presente para tecer em conjunto com ela a suas inúmeras possibilidades, sendo a plurissignificação uma delas, e na ausência desse leitor crítico, a literatura não pode ecoar, uma vez não estar associada ao elemento que a confere.

Os elementos de coesão e coerência interpretativas são essenciais para que o texto, independente do gênero a que pertence em caráter de classificação se alargue e repercuta no espaço da aprendizagem, podendo ser esse situado no âmbito escolar ou nas ínfimas possibilidades de outras estruturas em que ocorra a interação do leitor/texto simultaneamente, transformando-o em um espaço democrático de fortalecimento.

Aproximar a literatura da educação é o mesmo que reconhecê-la como visceral na construção de indivíduos críticos e que dialogam com as verdades, não somente a da moral, mas das diversas contidas no texto e que são encontradas à medida que esse suporte temático se instrumentaliza.

O aluno/a do ensino médio deve ser ensinado, treinado a dialogar com o texto no tom das possibilidades e não no trato de que a voz do seu criador é a predominante e final. Poder participar da construção de significados é apropriar-se do seu fortalecimento e reafirmar a constatação de que ele, o texto, só será significativo com a sua presença. Deve-se abandonar a ideia de que o leitor é apenas instrumento de realização do autor, uma vez ser tão somente apreciador daquilo lhe é oferecido, mas além de tudo isso, temos um outro sentido estabelecido, que é a influência da literatura em sociedade. Para Candido, (2006, pg.33)

Com efeito, a atividade do artista estimula a diferenciação de grupos; a
criação de obras modifica os recursos de comunicação expressiva; as obras
delimitam e organizam o público. Vendo os problemas sob esta dupla
perspectiva, percebe-se o movimento dialético que engloba a arte e a
sociedade num vasto sistema solidário de influências recíprocas.

O texto deve ter a capacidade de trazer mudança subjetiva e/ou objetiva ao leitor que contribui para a sua construção e nesse processo, introduzir as suas particularidades que intercambiadas com as do texto suscitam experiências diferentes e inovadoras que aguardavam pela sua descoberta porque é esse o processo de revelação, o achegar-se ao texto, uma vez ser o leitor o elemento de entrelaçamento textual e sem ele, não há vida textual a ser compartilhada. 
A literatura é capaz de transformar o indivíduo, grupos e em maior expansão, a própria sociedade. Cada leitor é responsável em transmitir conhecimento adquirido, no entanto, antes de tudo, começa por modificar a si mesmo e em consonância, o seu entorno sofrerá influências. Entendemos com isso que há um papel social da literatura quando da transformação da sociedade, provando que o texto discorrido no papel, sem a participação efetiva do leitor transformador, será apenas mais um escrito engavetado ou armazenado culturalmente.

A escola, o professor deve alertar ao aluno/a do ensino médio sobre o papel transformador que a literatura promove, deve-se explorar o universo de exemplos catalogados em que isso ocorrera, participando-os da vida que existe nos textos e das ações que ele, o próprio texto, promove na vida de todos. Nesse momento, é imprescindível salientar que a responsabilidade não está unicamente nas letras discorridas, mas na junção efetiva e produtiva do leitor/texto e que sem a sua participação, nada acontece em termos de transformação social.

A teoria literária não pode ser descartada no ensino da interpretação do texto literário, a aquisição desse conhecimento contribui para um melhor entendimento da produção e da contextualização em que o texto foi gerado. A sua qualidade, perfil e densidade estão também relacionados à sua origem e fundamentar-se no plano estético de composição resulta num melhor índice de aproveitamento daquilo que se extrai dele. (FILHO, 2002).

Esse é um momento importante nos estudos literários e que está relacionado quase que diretamente com a escola, acreditando ser esse o espaço pertinente que está sob a égide do professor, aquele que ampara e explicita de forma mais concreta e abrangente essas características mais específicas. Desse modo, os desafios do texto são mais preciosos quando em consolidação com a teoria e a orientação, que tornam o leitor capaz de elucidar um texto ímpar, fruto da junção teórica com a prática interpretativa.

Conduzir o aluno/a do ensino médio à teoria não é nada fácil, isso implica considerar de forma específica e abrangente elementos da língua portuguesa, significado e significante, figuras de linguagem e tantos outros elementos de composição textual. Como afirma Piglia (2006, p.19) 
A leitura literária não é feita pura e simplesmente da decodificação de signos, poderá partir também de uma desconstrução do sentido genérico da obra que, provavelmente, implicará uma visão muito particular do leitor, da capacidade de promover intertextos, originada da sua bagagem literária ou da falta dela. Com isso, também se constitui como leitor aquele que lê pouco, em fragmentos, com dificuldades, todavia, ainda consegue pôr significado à leitura, pois foi receptivo ao que leu, deixou-se ser "atingido" pela arte.

O texto literário não pode ser desmembrado do conhecimento de funcionamento da língua, não pode ser periférico pois é dela que o escritor faz uso para gerar a sua produção e será ela a responsável por gerir através do leitor, vários significados. Uma vez ser o estudo da língua parte integrante da produção de significados literários, cabe ao estudante do ensino médio a capacidade de relacionála ao texto literário. Enfatizar o estudo da língua é o mesmo que adequar, acomodar o texto ao espaço de ambivalência entre ela, a língua, e a sua gênese. Esta não se relaciona de forma pura e integral à sua formação histórica, mas ao resultado que a distingue de outras formas de expressão.

Tecer o texto literário não se detém à leitura de letras, significados e reconhecimento de qualidade de produção do seu autor, mas também, ao conhecimento expressivo de caracteres da língua que imbuídos de critérios legítimos, permitem ao leitor desdobrar o texto e para Koch, $(2010$, p. 3)

A Linguística Textual toma, pois, como objeto particular de investigação não mais a palavra ou a frase isolada, mas o texto, considerado a unidade básica de manifestação da linguagem, visto que o homem se comunica por meio de textos e que existem diversos fenômenos linguísticos que só podem ser explicados no interior do texto. O texto é muito mais que a simples soma das frases (e palavras) que o compõem: a diferença entre frase e texto não é meramente de ordem quantitativa; é, sim, de ordem qualitativa.

É hora de enxergar o efeito do que uma construção sintática pode gerar de forma mais aprofundada, o texto. O que precisa ser concluído pelo leitor é que o estudo gramatical gera uma equivalência superior a um montante de palavras, é preciso compreender de que forma essa língua funciona a partir dos jogos linguísticos que o autor promove para acomodar os elementos poéticos, narrativos em sua produção. O leitor deve ser capaz de reconhecer, identificar as diversas formas utilizadas na produção textual e a partir desse momento, enxergar o texto como um trabalho racional e prazeroso de tessitura. 
Desafiar o texto é papel do leitor maduro no momento de interação, reconhecer a sua importância tanto no aspecto de composição gramatical (linguagem) quanto do conjunto reunido e entender que a sua participação é fundamental para a compreensão e o aprendizado nele armazenados.

Em cada um de nós reside todo o conhecimento que adquirimos em nosso percurso de vida, e que mais precisamente está alojado em nossa mente. Por sermos seres sociais, necessitamos de uma ferramenta de comunicação que nos permita socializar esse conhecimento, fazer com que seja transmitido a outros seres sociais como nós, afim de que a sua expansão ganhe espaços ainda maiores e se propague como o elemento responsável por fazer e trazer diferenças ao ser e ao social.

Então, eis a palavra, a maior expressão do ser social e o meio de transmitir o conhecimento que, armazenado ao longo do tempo e estando esse ser inserido em um contexto de falantes de uma língua, utiliza-a para também receber conhecimento. Vemos que a linguagem dominada pelo falante é o canal, veículo de transmissão e captação de significados, interpretações e inúmeras comunicações retransmitidas ao seu semelhante, o que o faz compreender e utilizar essas experiências no particular e na coletividade.

Como pode-se perceber, os usuários de uma língua possuem uma memória que aqui podemos chamar ou caracterizar de memória coletiva, formada através da junção de experiências de cada ser social e que unidas e sistematizadas, uniformizam uma expressão coletiva. Porém, a cada mudança social, o ser internaliza novos conhecimentos e experiências, o que o faz ser responsável por atualizar esses dados junto a coletividade a fim de que todos caminhem com entendimento e compreensão.

O conhecimento de mundo pertencente a cada ser social depende da linguagem para ser revelado, cada indivíduo se expressa através do mecanismo que a ela the confere, estando sujeito aos seus princípios e às formas significativas que devem ser consideradas. O aluno/a do ensino médio, além de ser um leitor crítico, também deve estar apto na relação quanto ao uso da linguagem. Conferir essa necessidade, faz com que a sua leitura de mundo e do texto literário sejam de melhor modo mais explorados. Como afirma Paulino, (2005, p. 25)

A leitura se diz literária quando a ação do leitor constitui predominantemente uma prática cultural de natureza artística, estabelecendo com o texto lido uma interação prazerosa. O gosto da leitura acompanha seu desenvolvimento, 
sem que outros objetivos sejam vivenciados como mais importantes, embora possam também existir. $O$ pacto entre leitor e texto inclui, necessariamente, a dimensão imaginária, em que se destaca a linguagem como foco de atenção, pois através dela se inventam outros mundos, em que nascem seres diversos, com suas ações, pensamentos, emoções.

A relação intrínseca entre o leitor, texto literário e linguagem é indissociável, uma está para a outra, caminham juntas no princípio da aquisição do conhecimento e aqui, em relevância, o conhecimento de mundo atrelado ao tecer do texto literário em que o ser social acrescenta conhecimento e o recebe de volta, associados à linguagem, responsável em compartilhar outros textos construídos através da interpretação.

Não se tece um texto literário sem o conhecimento da linguagem, uma vez ser esse o mecanismo que deve anteceder a produção do discurso produzido por esse leitor crítico do ensino médio. Esse sujeito deve ser capaz de intervir na relação enunciado (unidade discursiva) e enunciação (ato de tomar a palavra) porque cada discurso tem a sua marca, o seu registro pessoal o que o faz único. O produtor do texto se expressa e observa como ser social constituído de conhecimento, e que trabalha sobre a relação social.

Entende-se que o funcionamento discursivo de um texto ocorre pela via de atribuição de sentidos e que a constituição da linguagem se instaura quando da relação entre o processo de produção e o resultado construído. O leitor crítico de ensino médio deve ser capaz de apresentar um sentido literal dessa relação, ou seja, demonstrar o seu nível de apreciação e análise do discurso.

O jogo de dominância e a relação de sentidos estendidos a outros textos é o resultado que deve predominar quando do estudo e análise do texto literário. Propor, encaminhar, orientar na condução da apreciação e interpretação textual deve ser uma constância nos estudos de literatura no ensino médio, uma vez não sendo a informação o caráter mais significativo desse texto, mas o momento em que o leitor de caráter e significado mais apurado continua a ser formado e em condição mais favorável à análise textual e do discurso.

\section{A Literatura Intermediada no Espaço Escolar}

Os estudos literários em âmbito escolar podem ser vistos como um núcleo de onde se extrai suporte para as demais áreas de ensino-aprendizagem, isso porque o 
texto literário está repleto de possibilidades de intercâmbio, o que aprimora e qualifica os objetos de estudo e enfatiza ao aprendiz que muito pode ser visto, contemplado dentro e fora da literatura, e que a sua capacidade interpretativa não se resume em seus textos, mas habilita o leitor a expandir-se em outros universos de compreensão.

Tratar de intercâmbio entre disciplinas é o mesmo que tratar sobre interdisciplinaridade, uma vez elevar o olhar para a multiplicação do conhecimento e encontrar em outras áreas a mesma finalidade. Isso ocorre no momento em que os professores das disciplinas e o sistema que rege o planejamento pedagógico da instituição de ensino compreendem, de forma mais específica, o poder que a literatura tem em penetrar nas camadas subjetivas de temas diversificados, levando elementos e exemplos de certificação para cada um deles. De acordo com Fazenda, (2008, p.82),

\begin{abstract}
A prática interdisciplinar pressupõe uma desconstrução, uma ruptura com o tradicional e com o cotidiano tarefeiro escolar. O professor interdisciplinar percorre as regiões fronteiriças flexíveis onde o "eu" convive com o "outro" sem abrir mão de suas características, possibilitando a interdependência, o compartilhamento, o encontro, o diálogo e as transformações. Esse é o movimento da interdisciplinaridade caracterizada por atitudes ante o conhecimento.
\end{abstract}

A desconstrução de que trata a interdisciplinaridade está nas vias do engessamento disciplinar a que se submeteu o ensino por muitos anos. Enxergar o conhecimento apenas por uma via exclusiva é não entender da natureza que cada disciplina porta em termos de contribuição do conhecimento que possui, somados a outros níveis de conhecimentos pertinentes às disciplinas. $E$ aqui trata-se da interdisciplinaridade que a literatura promove, ela é capaz de traduzir elementos internos em externos e vice-versa. A literatura pode traduzir, exemplificar, constatar o que fora dito pela disciplina em foco, o que torna o pensamento claro e em movimento, sendo capaz de direcionar-se para vários elementos que tenham relação com a temática em tratamento.

Dialogar conteúdos é a forma mais ampla e significativa que se pode estabelecer entre disciplinas curriculares, e em exclusivo, pulverizar a literatura em áreas que parecem ser difíceis de conter algo subjetivo, o que passa a ser surpreendente. O encontro de pontos comuns e incomuns é prazeroso de ser observado e experimentado, o que pode ser considerado positivo ao que se refere à leitura de literatura no ensino médio. 
É necessário, pois, que a escola, o professor de área não literária, estejam aptos e queiram intermediar a literatura em outro campo disciplinar. Não basta gostar de literatura e reconhecer o valor que possui, mas estar sensível ao momento em que essa relação pode ser estabelecida. É preciso recorrer à subjetividade literária que mora no mediador, se é que ele, o mediador/a/professor/a porta de leitura e interpretação literária, bem como a capacidade de interpretar e relacionar.

Vê-se que esse não é um trabalho de superfície, mas de profundidade, e é necessário que o regente esteja e seja preparado para estabelecer conexões literárias, é preciso estudo, sincronia e destreza para que essa ampliação seja feita paulatinamente e para isso, a escola deve entrar com o paradigma da relação entre disciplinas, efetivando-o em seu conteúdo programático como pauta de trabalho curricular. No entanto, a própria disciplina de literatura deve ser enxergada como núcleo, não a considerando superior ou exclusiva dentre as demais, porém, compreendendo que através dela, os canais de interação podem ser estabelecidos com veemência.

O entendimento de ser a literatura uma disciplina que pode reger o diálogo entre outras disciplinas, ainda é algo discutível em âmbito escolar, uma vez não ser ainda contemplada como possibilidade de intercambiar conteúdos. Vale ressaltar que a sua linguagem deve habitar a atmosfera do quadro de profissionais que capacitam os seus professores, é preciso que essa perspectiva subjetiva faça parte da composição pedagógica dos dirigentes escolares, caso contrário, permaneceremos na teoria das possibilidades.

O indivíduo em sociedade credita informações e aprendizados ao longo do processo de vida, não se pode crer que o conhecimento que dispõe e pratica seja algo inerente, pronto, mas adquirido e associado a tantos outros. É preciso compreender que o leitor percorreu caminhos de descobertas os quais buscou por iniciativa própria ou pela condução feita por um professor/orientador e que aqui vale ressaltar o papel do professor como mediador dessa condução, no momento em que transmite conhecimentos e contribui para a prática de novos aprendizados.

\section{Considerações Finais}

Muitas pesquisas, estudos e considerações são feitas em torno da importância da leitura, destacando-a como imprescindível para a aquisição de conhecimentos 
vários. É no diálogo entre leitor/a e literatura que se espera alcançar melhores níveis de aprendizagem e interpretação, universo capaz de elevar a capacidade de leitura do mundo e de si mesmo, enquanto indivíduo inserido em sociedade.

O aluno/a do Ensino Médio encontra dificuldades em reconhecer a importância da literatura como ferramenta basilar para o seu desempenho no aspecto da aprendizagem, que vai desde as disciplinas discursivas, até as disciplinas da área de exatas. Esse reconhecimento não está situado no campo da valorização do que ela representa, mas na internalização, no trazer para si a prática da leitura e da utilização do seu repertório como efeito de sentido.

Pode-se concluir que muitas são as falhas existentes no fluxo de interação entre o aluno/a do ensino médio, que vão desde o sistema educacional que rege as escolas públicas do Estado, até o momento em que a literatura é partilhada em sala de aula, englobando a metodologia aplicada aos estudos literários, a ausência de especificidade ao tratar da disciplina como núcleo, geradora de suporte para as demais disciplinas.

Importante ressaltar, como prática docente e discente, que o texto em sala de aula, reforça o posicionamento de entender do que a literatura é capaz de fazer com o indivíduo nas diferentes situações em que se coloca no mundo. Cada deslocamento Ihe dará significados diferentes e a sua apreciação sobre o mundo passa a ter sentido, não sendo visto apenas como um habitante, mas como aquele que pode transformar o seu espaço, levando qualidade, aprendizado e mudança de comportamento.

\section{Referências:}

ABRAMOVICH, F. Literatura Infantil: gostosuras e bobices. São Paulo: Scipione, 1995.

AZEVEDO, R. Qual a "função" da literatura? Carta na Escola, São Paulo n. 14, mar.2007.

CANDIDO, A. Vários escritos. Edição revista e ampliada. São Paulo: Duas Cidades, 1995.

CÂNDIDO, A. Literatura e Sociedade. 9 ed. Revista Ouro sobre Azul .Rio de Janeiro 2006.

CEREJA, W. R. Ensino de literatura: uma proposta metodológica para o trabalho com literatura. São Paulo: Atual, 2005. 
COSSON, R. Letramento literário: teoria e prática. São Paulo: Editora Contexto, 2009.

DIAS, W. J.A Importância Da Literatura Brasileira. Revisa Brasil Escola. 2017.

FAZENDA, I. C. A. O que é interdisciplinaridade? São Paulo: Cortez, 2008

FILHO, D. P. A Linguagem Literária. 3 ed. São Paulo: Ática, 2002.

FREIRE, P. A importância do ato de ler: em três artigos que se completam. São Paulo: Autores Associados, 2000.

JAUSS, H. R. A literatura como provocação: História da Literatura como provocação literária. Portugal: Passagens, 1993.

KOCH, I. V. A coesão textual. São Paulo: Contexto, 2010.

LAJOLO, M. Do Mundo da Leitura Para a Leitura do Mundo. $6^{\mathrm{a}}$ ed. Editora: Ática. São Paulo, 2008.

NETO, J. C. M. Tecendo a manhã, em Poesias Completas, José Olympio Editora, Rio, 1975.

PAULINO, G. Leitura literária: A Mediação Escolar. Belo Horizonte: FALE UFMG, 2004.

PAULINO, G. Alguma Especificidade da Leitura Literária. Belo Horizonte: Autêntica, 2005.

PEREIRA, H. B. Novas leituras da ficção brasileira no século XXI. São Paulo: Universidade Presbiteriana Mackenzie, 2009.

PIGLIA, R. O Último Leitor. Tradução Heloísa Jahn. São Paulo: Companhia das Letras, 2006.

WELLEK, R; WARREN, A. Teoria da Literatura e Metodologia dos Estudos Literários. Editora: Martins Fontes; São Paulo, 2003.

ZILBERMAN, R. A literatura e o ensino da literatura. Paraná: InterSaberes,2012. 